\title{
THE ASSOCIATION OF HEMOGLOBIN LEVELS WITH QUALITY OF LIFE AND PHYSICAL ACTIVITY IN HEMODIALYSIS PATIENT IN WANGAYA REGIONAL GENERAL HOSPITAL, DENPASAR
}

\author{
DIAN DANIELLA ${ }^{1}$, MARIANTO MARIANTO ${ }^{1}$, WAYAN SUNAKA I ${ }^{2}$ \\ ${ }^{1}$ General Practitioner, Wangaya Regional General Hospital, Denpasar, Indonesia. ${ }^{2}$ Internist, Department of Internal Medicine, Wangaya \\ Regional General Hospital, Denpasar, Indonesia. Email: dian.daniella@gmail.com
}

Received: 20 April 2020, Revised and Accepted: 30 May 2020

\section{ABSTRACT}

Objective: Anemia in chronic kidney disease (CKD) contributes in decreasing quality life, but specific hemoglobin associated with quality of life is still in debate. Anemia was thought to be one of contributing factors of low physical activity in CKD, but this finding is inconsistent across studies. This research study aims to investigate the association of hemoglobin levels with quality of life and physical activity in hemodialysis patients in our settings.

Methods: This study was conducted between March 30, 2020, and April 30, 2020, in hemodialysis unit, Wangaya Regional General Hospital, Bali. The study included 50 subjects on regular hemodialysis. Subject-reported quality of life was evaluated by interview, based on Kidney Disease Quality of Life (KDQOL)-36 ${ }^{\mathrm{TM}}$ questionnaire. Self-reported physical activity level was assessed by International Physical Activity Questionnaires (IPAQ).

Results: Quality of life in burden of kidney disease categories is different significantly between hemoglobin levels group (* $\mathrm{p}=0.034$ ). There is significant difference between hemoglobin levels $<8 \mathrm{~g} / \mathrm{dL}$ with 8.1-12 g/dL $(* * \mathrm{p}=0.01)$ and hemoglobin levels $<8 \mathrm{~g} / \mathrm{dL}$ with $>12 \mathrm{~g} / \mathrm{dL}\left({ }^{*} \mathrm{p}=0.034\right)$. For self-reported physical activity, hemoglobin level was not associated with physical activity in Fisher's exact test analysis $(\mathrm{p}=1.000)$.

Conclusion: We found that hemoglobin levels $>8 \mathrm{~g} / \mathrm{dL}$ were associated with higher quality of life in hemodialysis patient. Hemoglobin levels were not associated with physical activity. Recommended hemoglobin levels to support the best quality of life and physical activity without increasing mortality rate are still in need to be further evaluated.

Keywords: Hemodialysis, Hemoglobin, Quality of life, Physical activity, Chronic kidney disease

(C) 2020 The Authors. Published by Innovare Academic Sciences Pvt Ltd. This is an open access article under the CC BY license (http://creativecommons. org/licenses/by/4. 0/) DOI: http://dx.doi.org/10.22159/ajpcr.2020.v13i8.37983

\section{INTRODUCTION}

Chronic kidney disease (CKD) is still recognized as one of the major issues worldwide [1]. Besides the unfavorable disease outcome, CKD has also great economic burden which makes CKD a huge global problem [1,2]. In Indonesia, kidney disease ranks as the second most spender in the national health-care budget [3].

Since 2000, the prevalence of end-stage renal disease was $13,4 \%$ [4]. One in five men and one in four women between 65 and 74 years old suffered from CKD. According to data from Global Burden of Disease Study (GBD), in 2015, the mortality rate of CKD has increased by around 32\% since 2005 and reached 1.2 million globally [2,5]. Data also showed that there were 2 million death cases of CKD because of the limited access in renal replacement therapy [6]. CKD is often associated with reduced quality of life due to its complications [7]. Hemodialysis in CKD is performed to replace kidney function in end-stage renal disease. It is frequently associated with complications such as hemodynamic disorders, arrhythmia, cramping, nausea and vomiting, headache, and anemia [8].

Anemia, one of the most frequent complications of CKD, found increases in number as the disease progresses [9]. It was found in $50 \%$ of cases in CKD and $75 \%$ of people who are undergoing regular hemodialysis [10]. Erythropoietin deficiency, decreased red blood cells life span, abnormal iron metabolism, and chronic inflammation were the known mechanisms of anemia in CKD $[9,11]$. Anemia in CKD was also associated with the disease progression, increased mortality rate, and unfavorable outcome [12]. A study from Hoshino et al. showed that increased hemoglobin levels alleviated some symptoms in CKD such as depressions and insomnia in non-hemodialysis patients [13].
Low physical activity was another common problem found in CKD. Physical inactivity also affected some functional aspects including quality of life in CKD [14], even it was strongly associated with mortality [15]. Anemia was thought to be one of the contributing factors of low physical activity $[16,17]$ as well as low quality of life in CKD [18-20], but this finding was inconsistent across some studies [21-23]. In Indonesia, we use Kidney Disease Improving Global Outcomes (KDIGO) guidelines which also did not provide the specific hemoglobin to be achieved for better quality of life and physical activity [24]. Some of these studies result was not applicable in our settings. We also hardly found any studies assessing the quality of life and physical activity of hemodialysis patients, especially in our setting. Take into account these findings, we would like to investigate the correlation of hemoglobin levels with the quality of life and physical activity in hemodialysis patients in our settings.

This research study aims to investigate the association of hemoglobin levels with the quality of life and physical activity in hemodialysis patients in our settings.

\section{METHODS}

This study was conducted between March 30, 2020, and April 30, 2020, in hemodialysis unit, Wangaya Regional General Hospital, Denpasar, Bali. This study included 50 subjects with regular hemodialysis who met our criteria: (1) Age between 18 and 69 years old; (2) on regular hemodialysis twice a week for at least 3 months; and (3) had agreed to participate in our study. No subject undergoes peritoneal dialysis in this study. 
Subjects with a history of active bleeding and major surgery in the previous 3 months were excluded from the study. Exclusion criteria were also applied on subjects with wheelchair, physically or neurologically disabled, having mental and intellectual disorders, Alzheimer's disease, other conditions which heavily affected subjects to answer the interview questions, decided to stop participating in this study in the middle of interview, and no laboratory data measurements during the past 3 months.

This research was approved by the Research Ethics Committee of Wangaya General Hospital, 023/III/KEP/RSW/2020, according to the standards for conducting research with human beings, provided in Council for International Organizations of Medical Sciences (CIOMS) 2016 World Health Organization (WHO). The participants in this study were told about objective, risks and benefits, and asked to sign an informed consent form. A preannouncement of the study was performed by the staff nurse in charge before data collection. Data were taken directly by authors.

Of the 65 participants, one was excluded because not in our age settings, three subjects declined to participate. Sixty-one subjects consented to participate. Nine subjects were excluded (five subjects had a history of stroke and used wheelchair, one subject had a history of neurological disorder and wheel-chair dependent, one subject only communicated using local language, one subject suffered from mental disorder, and one subject had no recent laboratory test data and refused to do the blood test) and two subjects died during data collection process, resulting in 50 subjects included in final data analysis (Fig. 1).

Hemoglobin level and other laboratory parameters used for the study were measurements in the past 3 months. Anemia in our settings was all treated by erythropoietin- $\alpha$ subcutaneously. Iron injection was given to all hemodialysis patients every first date visit in the month. Most of the patients were given folic acid. Anemia was classified into $<8 \mathrm{~g} / \mathrm{dL}$, $8.1-12 \mathrm{~g} / \mathrm{dL}$, and $>12 \mathrm{~g} / \mathrm{dL}$.

Subject-reported quality of life was assessed using interview, based on Kidney Disease Quality of Life (KDQOL-36 ${ }^{\mathrm{TM}}$ ) questionnaire by research and development (RAND). The Indonesian version of KDQOL- $36^{\mathrm{TM}}$ had already been tested for validity and reliability by Supriyadi et al. [25]. The questionnaire consists of 36 questions which measures five aspects: (1) Symptom/problem list; (2) effects of kidney disease; (3) burden of kidney disease; (4) physical composite; and (5) mental composite. Each measurement would have a score range of $0-100$, with higher scores indicating better quality of life in each aspect.

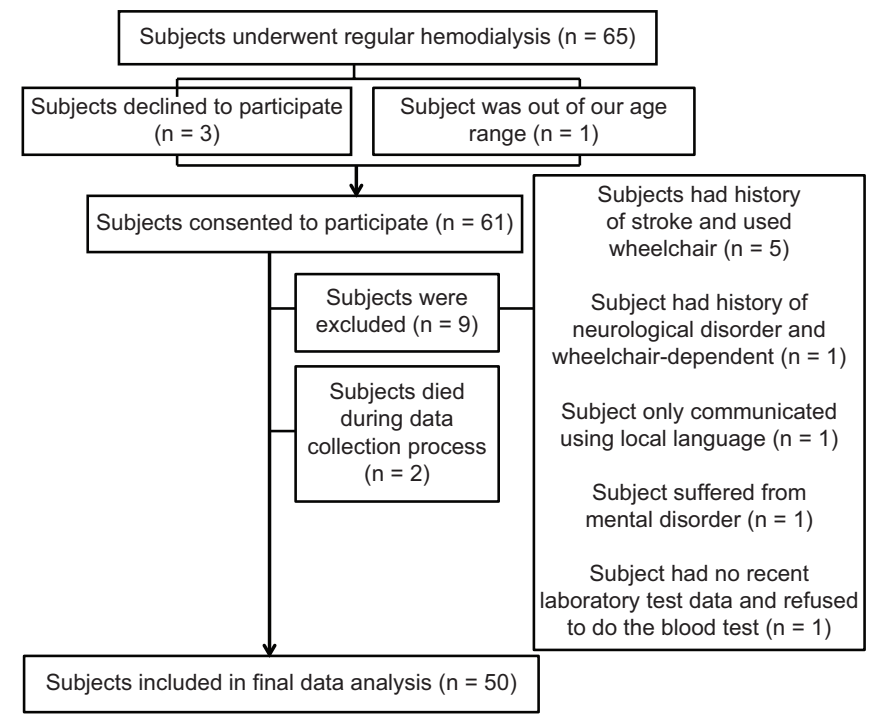

Fig. 1: Flowchart of subjects recruitment and exclusion
Self-reported physical activity level was assessed by International Physical Activity Questionnaire (IPAQ) which had been translated into Indonesian language. Physical activity was categorized into low, moderate, and high activity based on the interpretation.

Data analysis was performed using Statistical Package for the Social Sciences (SPSS) 25 software. Correlation of hemoglobin level and quality of life was analyzed using Kruskal-Wallis, followed by MannWhitney analysis to determine which groups had significant difference. For physical activity outcome, we used Fisher's exact analysis. For other parametric groups, Kolmogorov-Smirnov test was used for other variables group analysis.

\section{RESULTS}

\section{Demographic}

In Wangaya General Regional Hospital, all of our subjects had hemodialysis twice a week for $4.5 \mathrm{~h}$ each session. Subjects had hemodialysis from the arteriovenous shunt. Thirty-two subjects $(64 \%)$ are male, with most of them (24 subjects; $48 \%$ ) finished high school. Forty-three subjects (50\%) had hemoglobin levels 8.1-12 g/dL, $3(6 \%)$ of them had hemoglobin levels $<8 \mathrm{~g} / \mathrm{dL}$, and $4(8 \%)$ of them had hemoglobin levels $>12 \mathrm{~g} / \mathrm{dL}$. Eight subjects $(16 \%)$ had a history of hospitalization in the past 3 months. In terms of hemodialysis (HD) duration, most of the subjects (48 subjects) had HD $<5$ years, with most of them had hemoglobin levels 8.1-12 g/dL. Most frequent comorbidities in subject were hypertension $(90 \%)$ followed by diabetes mellitus (30\%). Only $8 \%$ of subjects had chronic hepatitis B and $2 \%$ of them had chronic hepatitis $\mathrm{C}$ infection (Table 1).

\section{Quality of life}

Subjects' quality of life was categorized into symptom/problem list, effects of kidney disease, burden of kidney disease, SF-12 physical mental health composite, and SF-12 mental health composite. In KDQOL-36 ${ }^{\mathrm{TM}}$ questionnaire, the higher the number, the better the quality of life. After analyzing the data, we found that quality of life in burden of kidney disease category was different significantly between hemoglobin levels group $\left({ }^{*} p=0.034\right)$ (Table 2 ). For the burden of kidney disease category, subjects with higher hemoglobin levels had a higher score $(25 \pm 16.5$ for hemoglobin levels $<8 \mathrm{~g} / \mathrm{dL}, 71.8 \pm 23.1$ for hemoglobin levels $8.1-12 \mathrm{~g} / \mathrm{dL}$, and $73.4 \pm 10.7$ for hemoglobin levels $>12 \mathrm{~g} / \mathrm{dL}$ ). In post hoc analysis, we found that between hemoglobin levels group, there were significant differences between hemoglobin levels $<8 \mathrm{~g} / \mathrm{dL}$ with hemoglobin levels $8.1-12 \mathrm{~g} / \mathrm{dL}\left({ }^{*} \mathrm{p}=0.01\right)$ and hemoglobin levels $<8 \mathrm{~g} / \mathrm{dL}$ with hemoglobin levels $>12 \mathrm{~g} / \mathrm{dL}\left({ }^{*} \mathrm{p}=0.034\right)$.

Age was associated with the burden of kidney disease categories $\left({ }^{* *} \mathrm{p}=0.000 ; \mathrm{r}=0.483\right)$ and physical health composite categories $\left({ }^{*} \mathrm{p}=0.016 ; \mathrm{r}=-0.339\right)$. Hospitalization in the past 3 months was associated with quality of life in burden of kidney disease category $\left({ }^{*} \mathrm{p}=0.038\right)$ and physical health composite category $\left({ }^{* *} \mathrm{p}=0.006\right)$. Hemodialysis duration was also associated with quality of life in burden of kidney disease category $\left({ }^{*} \mathrm{p}=0.028\right)$, physical health composite category $\left({ }^{*} \mathrm{p}=0.014\right)$, and mental health composite category $(\mathrm{p}=0.016)$. Other demographic factors were analyzed and not associated with quality of life. For comorbidities, hypertension was associated with physical health composite category $\left({ }^{*} \mathrm{p}=0.013\right)$, glomerulonephritis was associated with symptom/problem list category $(p=0.007)$, and urolithiasis was associated with the burden of kidney disease category $\left({ }^{*} \mathrm{p}=0.032\right)$. Other demographic factors were analyzed but not associated significantly with quality of life.

\section{Physical activity}

Almost all of our subjects (98\%) had low to moderate level of physical activity. For self-reported physical activity, 50\%, 48\%, and 2\% were categorized as low, moderate, and high physical activity, respectively. Only one subject had a high level of physical activity with hemoglobin levels 8.1-12 g/dL. In our study, hemoglobin levels were not associated with physical activity using Fisher's exact test $(p=1.000)$ (Table 3). Other demographic factors also were not associated with physical activity. 
Table 1: Baseline patient characteristics by hemoglobin levels

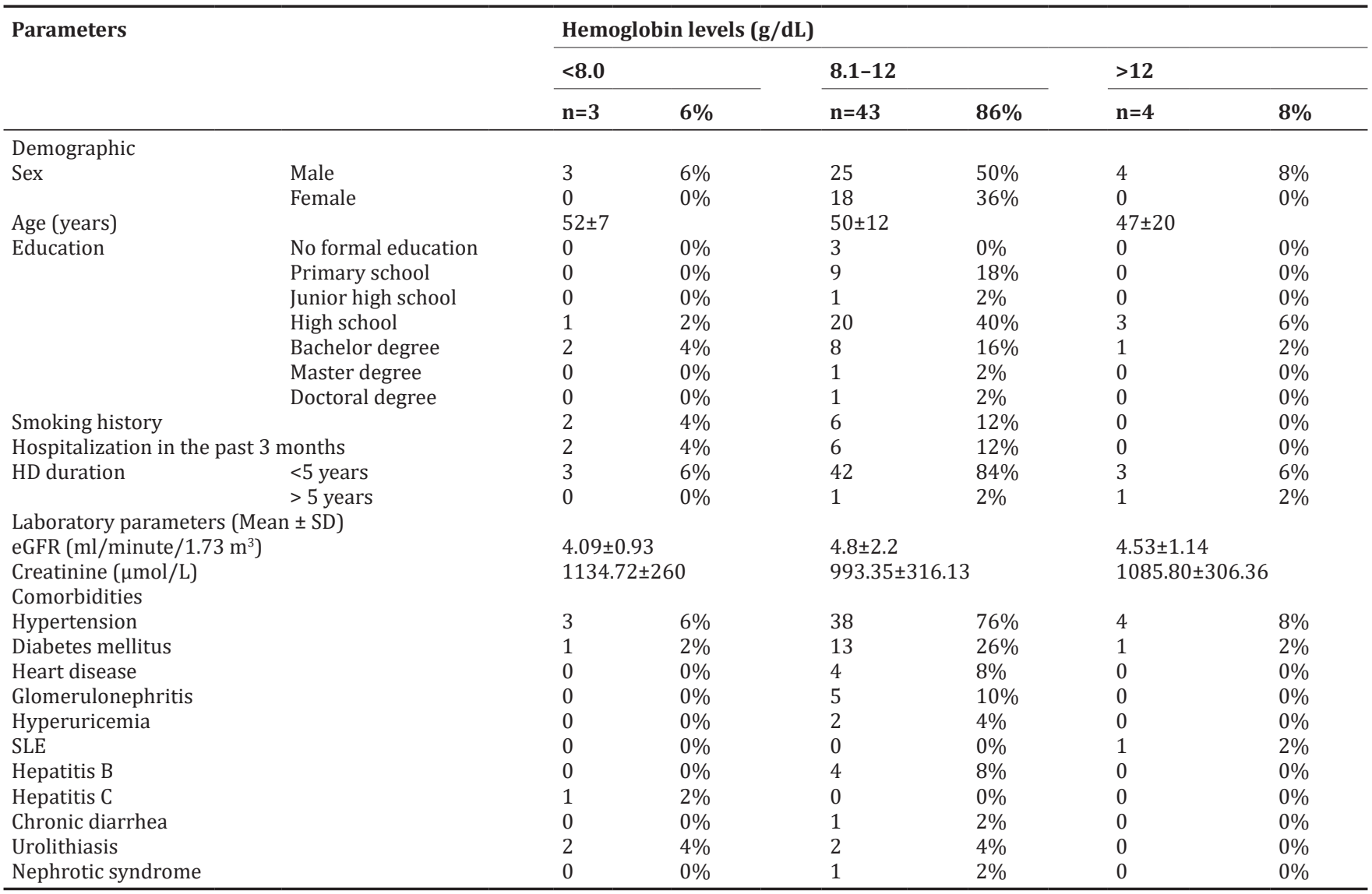

HD: Hemodialysis, eGFR: Estimated glomerular filtration rate, SLE: Systemic lupus erythematosus

Table 2: Quality of life by hemoglobin levels

\begin{tabular}{|c|c|c|c|c|c|c|c|}
\hline \multirow[t]{3}{*}{ Quality of life domain (Mean \pm SD) } & \multicolumn{6}{|c|}{ Hemoglobin levels (g/dL) } & \multirow[t]{3}{*}{$P$-value } \\
\hline & \multicolumn{2}{|c|}{$<8.0$} & \multicolumn{2}{|l|}{ 8.1-12 } & \multicolumn{2}{|l|}{$>12$} & \\
\hline & $n=3$ & $6 \%$ & $n=43$ & $86 \%$ & $n=4$ & $8 \%$ & \\
\hline Symptom/problem list & \multicolumn{2}{|c|}{$82.6 \pm 16.2$} & \multicolumn{2}{|l|}{$78.5 \pm 18.1$} & \multicolumn{2}{|c|}{$81.3 \pm 13.9$} & $\mathrm{p}=0.900$ \\
\hline Effects of kidney disease & \multicolumn{2}{|c|}{$53.1 \pm 27$} & \multicolumn{2}{|l|}{$81.3 \pm 19.2$} & \multicolumn{2}{|c|}{$91.4 \pm 6.9$} & $\mathrm{p}=0.095$ \\
\hline Burden of kidney disease & \multicolumn{2}{|c|}{$25 \pm 16.5$} & \multicolumn{2}{|l|}{$71.8 \pm 23.1$} & \multicolumn{2}{|c|}{$73.4 \pm 10.7$} & ${ }^{*} \mathrm{p}=0.034$ \\
\hline SF-12 physical health composite & \multicolumn{2}{|c|}{$25.6 \pm 7.5$} & \multicolumn{2}{|l|}{$38.1 \pm 10.2$} & \multicolumn{2}{|c|}{$33.1 \pm 11.4$} & $\mathrm{p}=0.079$ \\
\hline
\end{tabular}

SF: Short form

Table 3: Physical activity by hemoglobin levels

\begin{tabular}{lllllll}
\hline Physical activity & \multicolumn{5}{l}{ Hemoglobin levels (g/dL) } \\
\cline { 2 - 7 } & $\mathbf{8} 8.0$ & & $\mathbf{8 . 1 - 1 2}$ & $>\mathbf{1 2}$ & \\
\cline { 2 - 7 } & $\mathbf{n = 3}$ & $\mathbf{6 \%}$ & $\boldsymbol{n = 4 3}$ & $\mathbf{8 6 \%}$ & $\boldsymbol{n = 4}$ & $\mathbf{8 \%}$ \\
\hline Low & 2 & 4 & 21 & 42 & 2 & 4 \\
Moderate & 1 & 2 & 21 & 42 & 2 & 4 \\
High & 0 & 0 & 1 & 2 & 0 & 0 \\
\hline
\end{tabular}

\section{DISCUSSION}

\section{Quality of life}

The KDQOL-36 ${ }^{\mathrm{TM}}$ questionnaire is a valid and reliable tool for measuring quality of life in dialysis patients. It offers a deep interpretation of the variables related to the quality of life in HD patients [26]. Higher score in the questionnaire is interpreted as higher quality of life. Most of the subjects' complaints were of fluid restriction. In women, they usually complained about the bulging appearance of the $\mathrm{AV}$ shunt.

Quality of life in burden of kidney disease categories was different significantly between hemoglobin levels group $(* p=0.034)$. There was a significant difference between hemoglobin levels $<8 \mathrm{~g} / \mathrm{dL}$ with hemoglobin levels 8.1-12 $\mathrm{g} / \mathrm{dL}(* * \mathrm{p}=0.01)$ and hemoglobin levels $<8 \mathrm{~g} / \mathrm{dL}$ with hemoglobin levels $>12 \mathrm{~g} / \mathrm{dL}\left({ }^{*} \mathrm{p}=0.034\right)$. This suggested that hemoglobin levels $>8 \mathrm{~g} / \mathrm{dL}$ were associated with better quality of life.

This finding differed from Hoshino et al. and Finkelstein et al. studies which found that hemoglobin levels $>12 \mathrm{~g} / \mathrm{dL}$ were associated with a higher quality of life comparing to lower hemoglobin levels [13,27]. This difference might be caused by different studies' subjects. They used nondialysis subjects, whereas in this study, we used regular hemodialysis patients. In HD patients, high hemoglobin levels were found to have hemodynamic and symptomatic advantages, but it was often associated with higher mortality due to increased risk of hypertension and stroke. In terms of hemoglobin levels, recommended hemoglobin levels for dialysis 
patients are $11 \mathrm{~g} / \mathrm{dL}$, but the hemoglobin levels associated with an adverse event remain elusive [28]. In this study, we found that hemoglobin levels $>8 \mathrm{~g} / \mathrm{dL}$ was associated with better quality of life. This was probably due to most subjects who was unemployed and had low physical activity. Therefore, low hemoglobin levels did not affect their activities and quality of life. Another cause was due to their mental well-being, such as acceptance of their end-stage kidney disease. In Asian countries, especially in Indonesia, most general population had relatively high kinship with children and parents which they still lived together, further increasing the quality of life due to better family support. Grievance was usually reported in the first few months after CKD diagnosis and the need for hemodialysis were determined, but in our setting, hemodialysis was performed altogether with other patients, this might shorten the grieving period. All of the subjects have already passed the grieving period. Therefore, they tended to have better quality of life. This statement is supported by Cruz et al. which shows that low quality of life score was shown in an early stage of CKD, especially in the first two stages [22].

Other demographic factors that associated with quality of life are age, history of hospitalization in the past 3 months, hemodialysis duration, and comorbidities. Age and hospitalization are associated with the burden of kidney disease and physical health composite categories. The same result was found in a recent study in which age was associated with worse physical health and $>60$ years old was associated with worse quality of life [29]. Hemodialysis duration was also associated with quality of life in burden of kidney disease, physical health composite, and mental health composite categories. This finding was consistent with Seica et al. [30].

In comorbidities related factors, hypertension, glomerulonephritis, and urolithiasis are associated with quality of life. These comorbidities were associated with low quality of life and low score on SF-12 physical and mental health composite [22].

Most of the studies stated that education was associated with quality of life, Most of previous studies found that higher education level was associated with better quality of life $[22,26,30]$. However, in our studies, we found that education was not associated with quality of life. This is probably due to most of the patients who are high school graduates with enough capacity to understand their disease or has been given adequate information to fully comprehend their disease, or has passed the grieving period.

\section{Physical activity}

The IPAQ short form is a simple and quick self-reported questionnaire to assess subjects' physical activity. A study comparing IPAQ and accelerometer had moderate correlations among patients undergoing hemodialysis [31]. Another study comparing IPAQ and pedometer in CKD patients also found a modest correlation between both measurements [32]. Therefore, IPAQ is still preferred in this study in addition to the preferred age range included comparing to other questionnaires.

From the data analysis, the hemoglobin level was not correlated with physical activity level $(\mathrm{p}=1.000)$. This finding differs from the previous studies $[13,33]$. Hoshino et al. also found declining physical activity level decreased proportionally with lower Hb levels between $10.5 \mathrm{~g} /$ $\mathrm{dL}$ and $13 \mathrm{~g} / \mathrm{dL}$ [13]. Our study used the IPAQ questionnaire which depends on the memory of the subjects regarding the activity level. This may cause subjective findings in reporting the subjects' activity level. Results in the previous study also found that IPAQ may underestimate light physical activity [31]. This also may contribute to the difference in our results.

Creatinine level was previously reported being associated with individual muscle mass regardless of protein intake. High creatinine level was associated with increasing score of physical health composite [34]. However, in our study, creatinine was correlated with neither health-related quality of life nor physical activity. Studies had also found a relationship between declining glomerular filtration rate and physical function. We also did not find any relationship between these variables. No relationship was also found among our variables with level of activity.

There were a number of barriers affecting physical activity, such as using AV shunt in the dominant hand would hinder the subjects to do certain exercises and activity. Some patients also feared for feeling shortness of breath if they tried to exercise higher physical activity. These also affected our results.

There are a few limitations to our cross-sectional study. The routine erythropoietin injection makes the lesser variability of hemoglobin levels. The small sample size in our study might also make limited conclusions to extreme value of hemoglobin. Our study also did not include a control group. Other physical activity measurements such as pedometer and accelerometer were not used in our study due to limited funding in our study. In addition, accelerometer tends to underestimate the absolute amount of daily activity performed [35] and low-intensity walking. Pedometer may not be able to measure additional activities beyond walking [32]. We did not measure some other confounding factors such as nutritional status and serum calcium, phosphate, and albumin which could affect the result of our study.

\section{CONCLUSION}

We found that hemoglobin levels $>8 \mathrm{~g} / \mathrm{dL}$ was associated with the burden of kidney disease categories of quality of life in hemodialysis patients. In our study, hemoglobin level was not associated with physical activity. Recommended hemoglobin levels to support the best quality of life and physical activity without increasing mortality rate were still needed to be evaluated.

\section{ACKNOWLEDGMENT}

Authors would like to thank all participants and hemodialysis unit staff in Wangaya Regional General Hospital.

\section{CONFLICTS OF INTEREST}

Authors declare no conflicts of interest.

\section{AUTHORS' CONTRIBUTIONS}

Dian Daniella; wrote the paper, performed data collection, designed and performed data analysis, drafted the manuscript, and contributed to the final manuscript. Marianto; cowrote the paper, performed data collection, designed and performed data analysis, drafted the manuscript, and contributed to the final manuscript. I Wayan Sunaka; supervised the research and contributed to the final manuscript.

\section{AUTHORS' FUNDING}

The authors received no financial support for the research, authorship, and/or publication of this article.

\section{REFERENCES}

1. Yang M, Fox CH, Vassalotti J, Choi M. Complications of progression of CKD. Adv Chronic Kidney Dis 2011:18:400-5.

2. Luyckx VA, Tonelli M, Stanifer JW. The global burden of kidney disease and the sustainable development goals. Bull World Health Organ 2018;96:414-22

3. Kesehatan RI. Situasi Penyakit Ginjal Kronis. Pusat Data dan Informasi Kementrian Kesehatan RI; 2017. Available from: https://www.kemkes. go.id/download.php?file=download/pusdatin/infodatin/infodatin $\% 20$ ginjal\%202017.pdf. [Last accessed on 2020 Mar 10].

4. Hill NR, Fatoba ST, Oke JL, Hirst JA, O'Callaghan CA, Lasserson DS, et al. Global Prevalence of chronic kidney disease-a systematic review and meta-analysis. PLoS One 2016;11:e0158765.

5. Wang H, Naghavi M, Allen C, Barber RM, Bhutta ZA, Carter A, et al. Global, regional, and national life expectancy, all-cause mortality, and cause-specific mortality for 249 causes of death, 1980-2015: A 
systematic analysis for the global burden of disease study 2015. Lancet 2016;388:1459-544.

6. Liyanage $T$, Ninomiya $T$, Jha V, Neal B, Patrice HM, Okpechi I, et al. Worldwide access to treatment for end-stage kidney disease: A systematic review. Lancet 2015;385:1975-82.

7. Hudz N, Korytniuk R, Vyshnevska L, Wieczorek PP. Complex technological and biological research of solutions for peritoneal dialysis. Int J Appl Pharm 2018;10:59.

8. Lubis AA, Nasution A, Rosidah R. Pharmaceautical care improved the quality of life of patient with hemodialysis. Int J Curr Pharm Res 2019;11:49-54.

9. Wong MM, Tu C, Li Y, Perlman RL, Pecoits-Filho R, Lopes AA, et al. Anemia and iron deficiency among chronic kidney disease stages 3-5ND patients in the chronic kidney disease outcomes and practice patterns study: Often unmeasured, variably treated. Clin Kidney J 2019;sfz091:1-12.

10. Thomas R, Kanso A, Sedor J. Chronic kidney disease and its complications. Prim Care 2008;35:329-44.

11. Singh AK, Szczech L, Tang KL, Barnhart H, Sapp S, Wolfson M, et al. Correction of anemia with epoetin alfa in chronic kidney disease. N Engl J Med 2006;355:2085-98

12. Cases A, Egocheaga MI, Tranche S, Pallarés V, Ojeda R, Górriz JL, et al. Anemia of chronic kidney disease: Protocol of study, management and referral to nephrology. Nefrol Engl Ed 2018;38:8-12.

13. Hoshino J, Muenz D, Zee J, Sukul N, Speyer E, Guedes M, et al. Associations of hemoglobin levels with health-related quality of life, physical activity, and clinical outcomes in persons with 3-5 nondialysis CKD. J Ren Nutr 2020;S1051-2276(19):30414-5.

14. Tsai YC, Chen HM, Hsiao SM, Chen CS, Lin MY, Chiu YW, et al. Association of physical activity with cardiovascular and renal outcomes and quality of life in chronic kidney disease. PLoS One 2017;12:e0183642.

15. Painter P, Roshanravan B. The association of physical activity and physical function with clinical outcomes in adults with chronic kidney disease. Curr Opin Nephrol Hypertens 2013;22:615-23.

16. Odden MC. Association of chronic kidney disease and anemia with physical capacity: The heart and soul study. J Am Soc Nephrol 2004; 15:2908-15.

17. Schnelle J, Osterweil D, Globe D, Sciarra A, Audhya P, Barlev A. Chronic kidney disease, anemia, and the association between chronic kidney disease-related anemia and activities of daily living in older nursing home residents. J Am Med Dir Assoc 2009;10:120-6.

18. Murali R, Sathyanarayana D, Muthusethupathy MA. Assessment of quality of life in chronic kidney disease patients using the kidney disease quality of life-short form tm questionnaire in Indian population: A community based study. Asian J Pharm Clin Res 2015;8:271-4.

19. Thenmozhi P. Quality of life of patients undergoing hemodialysis. Asian J Pharm Clin Res 2018;11:219-23.

20. Tannor EK, Norman BR, Adusei KK, Sarfo FS, Davids MR,
Bedu-Addo G. Quality of life among patients with moderate to advanced chronic kidney disease in Ghana-a single centre study. BMC Nephrol 2019;20:122.

21. Ayoub A, Nelson K, Wood P, Hijjazi KH. The relationship between laboratory values and quality of life of dialysis patients in the United Arab Emirates. Ren Soc Australas J 2014;10:12-20.

22. Cruz MC, Andrade C, Urrutia M, Draibe S, Nogueira-Martins LA, de Sesso RC. Quality of life in patients with chronic kidney disease. Clin Sao Paulo Braz 2011;66:991-5.

23. Venkateswaramurthy N, Islam MS, Habeeba RC, Sambathkumar R. Assessment of quality of life in dialysis and non-dialysis chronic kidney disease patients. Int J Pharm Sci Res 2019;10:2970-4.

24. Finkelstein FO, Finkelstein SH. The impact of anemia treatment on health-related quality of life in patients with chronic kidney disease in the contemporary era. Adv Chronic Kidney Dis 2019;26:250-2.

25. Supriyadi RF, Gondodiputro RS, Darmawan G. Validity and reliability of the Indonesian version of kidney disease quality of life (KDQOL-36) questionnaire in hemodialysis patients at Hasan Sadikin hospital, Bandung, Indonesia. Acta Med Indones 2019;51:318-23.

26. Sadeghi M, Ebrahimi H, Abbasi M, Norouzadeh R. Relationship between anemia, quality of life, and laboratory indices in hemodialysis patients. Saudi J Kidney Transpl 2016;27:1063-7.

27. Finkelstein FO, Story K, Firanek C, Mendelssohn D, Barre P, Takano T, et al. Health-related quality of life and hemoglobin levels in chronic kidney disease patients. Clin J Am Soc Nephrol 2009;4:33-8.

28. Jing Z, Wei-Jie Y, Nan Z, Yi Z, Ling W. Hemoglobin targets for chronic kidney disease patients with anemia: A systematic review and metaanalysis. PLoS One 2012; 7:e43655.

29. Gerasimoula K, Lefkothea L, Maria L, Victoria A, Paraskevi T, Maria P. Quality of life in hemodialysis patients. Mater Soc Med 2015;27:305.

30. Seica A, Segall L, Verzan C, Vaduva N, Madincea M, Rusoiu S, et al. Factors affecting the quality of life of haemodialysis patients from Romania: A multicentric study. Nephrol Dial Transpl 2008;24:626-9.

31. Da Rosa CS, Gracia-Marco L, Barker AR, Freitas IF Jr., Monteiro HL. Assessment of physical activity by accelerometer and IPAQshort version in patients with chronic kidney disease undergoing hemodialysis. Blood Purif 2015;40:250-5.

32. Lou X, He Q. Validity and reliability of the international physical activity questionnaire in Chinese hemodialysis patients: A multicenter study in China. Med Sci Monit 2019;25:9402-8.

33. Gomes EP, Reboredo MM, Carvalho EV, Teixeira DR, D’Ornellas CL, Filho GF, et al. Physical activity in hemodialysis patients measured by triaxial accelerometer. BioMed Res Int 2015;2015:1-7.

34. Yusop NB, Mun CY, Shariff ZM, Huat CB. Factors associated with quality of life among hemodialysis patients in Malaysia. PLoS One 2013;8:e84152.

35. Welk GJ, Mcclain J, Ainsworth BE. Protocols for evaluating equivalency of accelerometry-based activity monitors. Med Sci Sports Exerc 2012;44:S39-49. 